\title{
Prevalence, Development, and Significance of Ascochyta Blight Caused by Peyronellaea pinodes in Pisum elatius Populations Growing in Natural Ecosystems
}

\author{
M. Golani, O. Frenkel, M. Bornstein, R. Shulhani, S. Abbo, and D. Shtienberg
}

First, second, third, fourth, and sixth authors: Department of Plant Pathology, Volcani Center, Agricultural Research Organization, Bet-Dagan 50250, Israel; and first and fifth authors: The Robert H Smith Faculty of Agriculture, Food and Environment, The Levi Eshkol School of Agriculture, The Hebrew University of Jerusalem, Rehovot 7610001, Israel.

Accepted for publication 21 March 2016.

\begin{abstract}
Golani, M., Frenkel, O., Bornstein, M., Shulhani, R., Abbo, S. and Shtienberg, D. 2016. Prevalence, development, and significance of Ascochyta blight caused by Peyronellaea pinodes in Pisum elatius populations growing in natural ecosystems. Phytopathology 106:833-841.

Wild Pisum populations prevail in Israel in regions with diverse climatic conditions. A comprehensive survey was conducted in the winters of 2007-08 and 2008-09 at two sites in northern Israel, aiming to (i) document the density of Pisum elatius plants in natural ecosystems and elucidate factors related to their initial infection by Ascochyta blight and (ii) determine the factors governing disease development over time on individual plants. The surveyors identified $P$. elatius plants growing in designated quadrats, inspected each

ubiquitous in Pisum elatius populations at both survey sites in both seasons. However, the total leaf area exhibiting disease symptoms of individual plants was very low, and stem and pod infections were rarely observed. Based on analyses of the survey data, it was suggested that, in natural ecosystems, the teleomorph stage of Peyronellaea pinodes serves as the main source of the primary and the secondary inoculum of the disease. In addition, it was found that infected leaves dropped off soon after infection, thereby precluding development of stem lesions. The plants continued growing and did not die; thus, they overcame the disease and could be considered "cured". This phenomenon was examined and confirmed in artificially inoculated, potted-plant experiments. It would be worthwhile to exploit the potential of this unique resistance mechanism as a tool for Ascochyta blight management in pea breeding.
\end{abstract} plant visually, and recorded the incidence and severity of its Ascochyta blight symptoms. Ascochyta blight, caused by Peyronellaea pinodes, was
Additional keywords: black spot, natural habitats.
Pea (Pisum sativum L.) is an important cool-season legume in cereal-based cropping systems in temperate regions across Europe, Asia, and North America, and a major traditional protein crop in the East African highlands. In addition, pea is often grown as a fodder crop and as a source of green seed for the food industry, as well as a vegetable crop (Davies 1993). Pea, grown on approximately 6.2 million ha, with total annual production ranging between 10 and 11 million tons, ranks third, after dry bean and chickpea, among the food legumes (FAOSTAT 2013).

There are several approaches to pea taxonomy (Ladizinsky and Abbo 2015). Features common to all the taxonomic systems proposed for Pisum are (i) the independent and distinct status of $P$. fulvum, and (ii) the close genetic affinity among the wild elatius, wild humile, and domesticated sativum forms. These features are well reflected in both classical taxonomy (Ben-Ze'ev and Zohary 1973; Waines 1975) and phylogenetic analyses based on DNA markers (Ellis 2010; Jing et al. 2010, 2012; Vershinin et al. 2003).

The three wild Pisum forms have distinct ecological affinities, as expressed in their distribution patterns (Ladizinsky and Abbo 2015). P. elatius is a pan-Mediterranean element, with distribution extending into temperate central European regions and from the Middle East through the Trans-Caucasus (Davis 1970; Ladizinsky and Abbo 2015). Throughout its distribution, P. elatius occupies a

Corresponding author: D. Shtienberg; E-mail address: danish@volcani.agri.gov.il

*The $\boldsymbol{e}$-Xtra logo stands for "electronic extra" and indicates that two supplementary figures are published online.

http://dx.doi.org/10.1094/PHYTO-02-16-0064-R

(C) 2016 The American Phytopathological Society rather narrow and specific ecological range. For example, in Israel, it is mostly found along humid creeks and running streams on Mount Carmel, and in western and upper Galilee and the upper Jordan Valley. In general, P. elatius has a rather patchy distribution, with fairly large populations extending over several hundred meters along forested creeks; however, very sparse populations and even solitary plants are often encountered. Seedling establishment is somewhat erratic from year to year but it seems to sustain a solid seed bank, at least in the larger known populations (Abbo et al. 2013b). In many of its habitats, it is accompanied by P. fulvum.

Wild $P$. humile is known from Turkey and Syria, and its distribution overlaps that of $P$. fulvum in certain locations in Israel, where they often share microhabitats (Abbo et al. 2008). In contrast to P. elatius and P. humile, P. fulvum is abundant in areas with lower (winter only) annual rainfall in the eastern Mediterranean districts of Israel, Jordan, Lebanon, Syria, and, rarely, Turkey (Ladizinsky and Abbo 2015; Mattatia 1977). In most of its habitats, it forms patchy but densely populated stands (Abbo et al. 2013a,b; Maxted and Ambrose 2001).

Ascochyta blight is a serious disease of pea crops worldwide (Bretag et al. 2006; Khan et al. 2013). The disease is caused by a complex of four fungal pathogens: Peyronellaea pinodes (Berk. \& A. Bloxam.) Petrak, Phoma medicaginis var. pinodella (L. K. Jones) Morgan-Jones \& K. B. Burch, Ascochyta pisi Lib., and Phoma koolunga (Davidson et al. 2009). It is widely accepted that Peyronellaea pinodes is the most important and damaging pathogen in the complex (Bretag et al. 2006; Tivoli and Banniza 2007). In pea crops, early symptoms most commonly are observed under the plant canopy, on the lower leaves, where conditions are more humid. Symptoms first appear as small, purplish-brown, irregular flecks. Under continuing humid conditions, the flecks enlarge and coalesce, causing the lower leaves to become completely blighted. Leaf infections enable development 
of the pathogen toward the stem, where lesions girdle and weaken the stem, contributing to crop lodging and yield loss. Disease lesions develop on pods under prolonged moist conditions, or if the crop has lodged. These lesions initially are small and dark but may become extensive and lead to early pod senescence. Severe pod infection may result in small, shrunken, or discolored seed. In general, Ascochyta blight symptoms on wild Pisum plants growing in natural ecosystems resembled the above description for domesticated pea (Kaiser et al. 1998) (D. Shtienberg, personal observations).

In commercial pea crops, Ascochyta blight is a polycyclic disease that can develop rapidly during periods of wet weather and moderate temperatures. Primary inoculum may originate from infected seed, soil, infected pea stubble, volunteer plants, or wild legume species (other than Pisum spp.). It was repeatedly demonstrated that ascospores, released from matured pseudothecia that developed on infected stubble from the previous season, form a major source of initial inoculum in commercial fields (Bretag and Ramsey 2001; Roger and Tivoli 1996; Salam et al. 2011). Secondary inoculum consists of pycnidiospores that develop in pycnidia formed in lesions on leaves, stems, and pods. However, unlike other Ascochyta blight pathogens, $P$. pinodes produces pseudothecia alongside pycnidia during the growth season. Consequently, ascospores constitute an important source of secondary inoculum. Pycnidiospores are dispersed over short distances by rain splashes, whereas ascospores may be airborne across long distance (Bretag et al. 2006; Khan et al. 2013; Roger and Tivoli 1996; Schoeny et al. 2007). There are only two anecdotal reports of the occurrence of Ascochyta blight in natural ecosystems. The first, from Israel, pointed out that Ascochyta blight did not assume epidemic proportions in wild pea populations (Dinoor 1974); the second, from Bulgaria, described the isolation of $P$. pinodes from Pisum elatius (Kaiser et al. 1998). To the best of our knowledge, the epidemiology of Ascochyta blight in natural ecosystems has not been studied yet.

Several authors such as Dinoor and Eshed (1984), Gladieux et al. (2015), and Stukenbrock and McDonald (2008) have elaborated on the reasons for studying the epidemiology of plant diseases in natural ecosystems. Such studies have practical implications for disease management in agroecosystems and may contribute to identification of disease resistance, defense strategies, and biocontrol agents. Studying the epidemiology of plant diseases in natural ecosystems is important because severe epidemics in natural ecosystems may devastate beneficial wild populations. Pandemics in natural ecosystems may damage wild populations that, in turn, may affect humans directly or indirectly. Study of plant diseases in natural ecosystems may also improve our understanding of host-pathogen coevolution (Dinoor and Eshed 1984; Gladieux et al. 2015; Stukenbrock and McDonald 2008). With respect to the Peyronellaea pinodes-wild Pisum sp. pathosystem, most research efforts have addressed the host. Attempts were made to identify sources for alleles or allele combinations that were not fully exploited for resistance breeding (Bretag et al. 2006; Clulow et al. 1991; Fondevilla et al. 2005; Jha et al. 2012; Jing et al. 2010; Muehlbauer et al. 1994; Weimer 1947; Wroth 1998). A few studies addressed the pathogen: Le May et al. (2014) examined the host range of $P$. pinodes originated from wild Pisum spp. and Peever et al. (2007) studied the evolutionary relationships among Ascochyta spp. of wild and domesticated hosts in the legume tribes Cicereae and Vicieae.

The prevalence of wild Pisum populations in Israeli regions with diverse climatic conditions provides a unique opportunity to study the epidemiology of Ascochyta blight in natural habitats. The coexistence of wild Pisum populations alongside pea crops in the Levant for more than 10 millennia is likely to be reflected in the genetic structure of the pathogen populations. Therefore, a study of these pathosystems may shed light on the interrelationships between the two pathogen demes (i.e., wild versus cultivated fields). It was recently reported that $P$. pinodes induced Ascochyta-like symptoms on Pisum sativum, P. fulvum, and P. elatius. Furthermore, temperature responses, spore germination rates, and aggressiveness of the isolates sampled from $P$. sativum did not differ from those sampled from adjacent or distant wild $P$. fulvum and $P$. elatius populations (Golani et al. 2016).

In the present study, the epidemiology of Ascochyta blight in natural ecosystems was explored. Because there are no published data on this subject, our basic assumption was that the epidemiology of Peyronellaea pinodes in natural ecosystems would be comparable with that reported for pea crops. It was decided to focus on Pisum elatius, which is cross-compatible with domesticated pea (Ben-Ze'ev and Zohary 1973), and to document disease development at two sites that differ in climatic conditions and are located at differing distances from commercial pea-production fields. Because the density of $P$. elatius plants varies spatially (Ladizinsky and Abbo 2015), we hypothesized that, under given environmental conditions, the prevalence of Ascochyta spp.-infected plants would be proportional to plant density; disease severity is known to be greater in dense than in sparse plant populations. Furthermore, we assumed that Ascochyta blight severity of individual plants reflected the prevalence of the disease in the surrounding population based on the well-established principle that disease severity increases proportionally to intensification of plant disease incidence. Accordingly, the objectives of the present study were to (i) document the density of $P$. elatius in natural ecosystems and to elucidate the factors related to their initial infection by Peyronellaea pinodes and (ii) determine the factors governing disease development over time in individual plants.

\section{MATERIALS AND METHODS}

Survey of wild Pisum elatius populations. A comprehensive survey was conducted in the winters of 2007-08 and 2008-09 at two sites in northern Israel. The first site was in the gorge of A'mud Creek and the second in the gorge of Kziv Creek. A'mud Creek arises in the upper Galilee Mountains at an altitude of $800 \mathrm{~m}$; it flows to the southeast and terminates in the Sea of Galilee at $200 \mathrm{~m}$ below sea level. This survey was carried out close to Kibbutz Hoquq $\left(32^{\circ} 52^{\prime} 02^{\prime \prime} \mathrm{N} ; 35^{\circ} 30^{\prime} 14^{\prime \prime} \mathrm{E}\right)$ at an altitude of $120 \mathrm{~m}$ below sea level. Kziv Creek also arises in the upper Galilee Mountains at an altitude of $800 \mathrm{~m}$ but it flows to the west toward the Mediterranean Sea. This survey was carried out close to Moshav A'vdon $\left(32^{\circ} 02^{\prime} 35^{\prime \prime} \mathrm{N}\right.$; $\left.35^{\circ} 11^{\prime} 06^{\prime \prime} \mathrm{E}\right)$ at an altitude of $130 \mathrm{~m}$. The average annual precipitation at the survey sites is 390 and $700 \mathrm{~mm}$, respectively (http://www.meteo. co.il). In recent decades, domesticated pea was rarely, if at all, grown in the vicinity of the Kziv site; the main pea-production area in Israel (Bet-Shean valley) is approximately $40 \mathrm{~km}$ south of the A'mud site.

At each site, eight strips, each of 1 by $30 \mathrm{~m}$, were designated and marked in situ. In 2008-09, each strip was subdivided into 30 quadrats of $1 \mathrm{~m}^{2}$ each. Two or three individuals performed the survey once per month from January through March 2008 and from November 2008 through April 2009. The surveyors identified the Pisum elatius plants growing in the designated quadrats, inspected each plant visually, and recorded the total number of leaves and the number of leaves exhibiting typical Ascochyta blight symptoms.

Data recorded in the survey were processed as follows. For some analyses, plant densities of both asymptomatic and symptomatic plants in each $30-\mathrm{m}^{2}$ strip or in each $1-\mathrm{m}^{2}$ quadrat were computed. In other analyses, the numbers of plants growing in distinct foci were calculated according to the criterion that plants further than $1 \mathrm{~m}$ apart belonged to different foci. The frequency distribution of foci, according to their size, was then computed. Plant disease incidence per strip (i.e., the proportion of plants in each strip that exhibited any level of Ascochyta blight symptoms) and plant disease severity (i.e., the proportion of the total number of leaves on a plant that exhibited Ascochyta blight symptoms) were also computed. The relationship between plant density and plant disease incidence per strip was computed to elucidate whether disease intensity was proportional to plant density. Likewise, the relationship between plant disease incidence and disease severity was computed to elucidate whether disease severity on individual plants 
was proportional to disease incidence among the population. In the latter analysis, disease severity data were square-root transformed to stabilize the variance and linearize the regression equation (Seem 1984).

Isolation and identification of the causal agent. Plant parts bearing Ascochyta blight-like symptoms were sampled occasionally to verify the identity of the causal agent. The procedures were similar to those described by Golani et al. (2016). In general, symptomatic tissues were inspected for the presence of pycnidia under a binocular microscope at $\times 20$ magnification. Sections bearing pycnidia were disinfested for $1 \mathrm{~min}$ in a domestic bleach solution of sodium hypochlorite at $10 \mathrm{~g} / \mathrm{liter}$, washed once with sterile water, and dried on sterile filter paper. The samples were then placed on 9-cm petri dishes with potato dextrose agar (Difco) and incubated in a growth chamber at $22 \pm 1^{\circ} \mathrm{C}$ under a cycle of alternating $12 \mathrm{~h}$ of near-UV light and $12 \mathrm{~h}$ of darkness for 10 days. Then, a disk was taken aseptically from the margin of the growing colony and transferred to a new petri dish. After 1 week, 5-mm disks bearing pycnidia were sampled, dipped in $1 \mathrm{ml}$ of distilled water, and agitated. Subsamples of $120 \mu \mathrm{l}$ were evenly distributed on another set of petri dishes and incubated at $22^{\circ} \mathrm{C}$. Single-spore cultures were then prepared and used for identification and further experimentation. The fungi were first identified morphologically by comparing conidial size, number of conidial cells, and formation of chlamydospores with those described previously by Jones (1927) and Peever et al. (2007). Then, isolates were identified by using DNA polymorphism, as described by Golani et al. (2016). In all isolations, the causal agent was identified and confirmed to be Peyronellaea pinodes.

Experiments under controlled environments. Artificialinoculation experiments were performed to explore the following phenomenon occurring in the natural habitats. It was observed that symptomatic leaves located in the lower layers of the plants dropped off and, after a while, the diseased plants appeared "cured" and escaped the disease. In these experiments, two wild lines (Pisum elatius and $P$. fulvum; originating from upper Galilee) and one domesticated garden pea cultivar (P. sativum 'Karina') were grown in 1-liter pots filled with a 1:1 tuff/peat mixture, with 2 plants/pot. The plants were kept in a growth chamber at $22 \pm 1{ }^{\circ} \mathrm{C}$ under a cycle of $12 \mathrm{~h}$ of light alternating with $12 \mathrm{~h}$ of darkness, and were irrigated and fertilized as needed. Two weeks after planting, the plants were inoculated with spore suspensions of Peyronellaea pinodes isolates originating from the corresponding hosts at $5 \times 10^{5}$ spores $/ \mathrm{ml}$, as previously described (Golani et al. 2016). Tween $80(0.1 \%)$ was added to the solution before inoculation. The plants were sprayed to runoff by means of an air-pressure hand sprayer, covered with two layers of plastic bags for $24 \mathrm{~h}$ to preserve leaf wetness, and returned to the growth chamber. Disease severity (i.e., the proportion of leaf area exhibiting typical Ascochyta blight symptoms) was assessed visually for each leaf. Assessments were performed every 2 or 3 days by the same individual until 15 days after inoculation. The following linear hierarchic-factorial analysis of variance (ANOVA) model was used for data analysis: $\mathrm{Y}_{\mathrm{ijklm}}=\mu+\mathrm{OH}_{\mathrm{i}}+\mathrm{CH}_{\mathrm{j}}+\mathrm{I}_{\mathrm{k}}\left[\mathrm{OH}_{\mathrm{i}}\right]+$ $\mathrm{LP}_{1}+\mathrm{OH}_{\mathrm{i}} \times \mathrm{CH}_{\mathrm{ij}}+\mathrm{OH}_{\mathrm{i}} \times \mathrm{LP}_{\mathrm{i} 1}+\mathrm{I}_{\mathrm{k}}\left[\mathrm{OH}_{\mathrm{i}}\right] \times \mathrm{CH}_{\mathrm{j}}+\mathrm{I}_{\mathrm{k}}\left[\mathrm{OH}_{\mathrm{i}}\right] \times \mathrm{LP}_{1}+\mathrm{CH}_{\mathrm{j}} \times$ $\mathrm{LP}_{\mathrm{j} 1}+\mathrm{OH}_{\mathrm{i}} \times \mathrm{CH}_{\mathrm{j}} \times \mathrm{LP}_{\mathrm{ijl}}+\mathrm{I}_{\mathrm{k}}\left[\mathrm{OH}_{\mathrm{i}}\right] \times \mathrm{CH} \times \mathrm{LP}_{\mathrm{j} 1}+\varepsilon_{\mathrm{ijklm}}$, where $\mathrm{Y}_{\mathrm{ijklm}}=$ final recorded disease severity (arcsin transformed), $\mu=$ grand mean, $\mathrm{OH}_{\mathrm{i}}=$ original host plant (fixed effect), $\mathrm{CH}_{\mathrm{j}}=$ inoculated host plant (fixed effect), $\mathrm{I}_{\mathrm{k}}\left[\mathrm{OH}_{\mathrm{i}}\right]=$ isolate within host (random effect), $\mathrm{LP}_{1}=$ leaf position (fixed effect), and $\varepsilon_{\mathrm{ijklm}}=$ random error. Plants sprayed with water and maintained under similar conditions served as untreated controls. There were five replicates (pots) per treatment and the experiment was repeated once. Because the results were comparable, data recorded for one of the experiments are presented herein. Statistical analyses were performed with the JMP 6 software (SAS Institute).

Spatial distribution of Pisum elatius in natural ecosystems. Morisita's index of dispersion $\left(I_{\delta}\right)$ (Morisita 1962) was used to determine whether Pisum elatius plants growing in natural ecosystems were distributed at random or in aggregates. Computation was carried out for assessments performed soon after disease onset, in December 2008. In each transect, the locations of the plants were recorded in $1-\mathrm{m}^{2}$ quadrats. Morisita's $I_{\delta}$ was calculated as follows:

$$
I_{\delta}=n\left\{\left[\left(\sum_{i} x_{i}^{2}\right)-\sum_{i} x_{i}\right] /\left[\left(\sum_{i} x_{i}\right)^{2}-\sum_{i} x_{i}\right]\right\}
$$

where $n$ is the number of quadrats per strip $(n=30)$ and $x_{i}$ is the number of $P$. elatius plants in quadrat $i(i=1 \ldots n)$. The $I_{\delta}$ index values exhibited a statistically significant departure from a random distribution $\left(I_{\delta} \neq 1.0\right)$ according to comparison of $F_{O}$ values with the values of $F_{\infty}{ }^{n-1}(\alpha)$ by Morisita's (1962) method: $F_{0}=\left[I_{\delta} \times(N-1)+n-\mathrm{I}\right] /(n-1)$, where $n$ is the number of quadrats and $N$ is the total number of symptomatic plants $\left(=\Sigma_{i} x_{i}\right)$. Different $I_{\delta}$ values offer two different interpretations, which suggest two different situations: when $I_{\delta}$ - index values did not differ significantly from 1.0, the distribution of symptomatic plants was interpreted as random; when $I_{\delta}$ - index values were significantly greater than 1.0 , the distribution of symptomatic plants was interpreted as aggregated (Morisita 1962).

\section{RESULTS}

The density of $\boldsymbol{P}$. elatius in natural ecosystems and factors associated with their initial infection by Peyronellaea pinodes. In the surveyed areas, Pisum elatius plants were distributed in discrete patches. Along the creeks, we recorded strips with no or just a few $P$. elatius plants, and others with dense populations (Fig. 1). Similarly, within each of the sampled strips, there were gaps with no P. elatius plants, sites with only one or two individuals, and patches harboring many plants. An example of the spatial distribution of P. elatius plants in two strips is presented in Figure 2. In 12 of the 16 strips sampled in December 2008, values of Morisita's $I_{\delta}$ were significantly $(P<0.05)$ greater than 1.0 , which matches the observation that $P$. elatius plants were spatially dispersed in aggregates. For A'mud Creek, the significant $I_{\delta}$ values ranged from 1.98 to 4.95 and, for Kziv Creek, from 3.97 to 10.7. The frequency distribution of sizes of $P$. elatius foci further highlights the patchy distribution of this species in its natural habitats. Approximately one-third of the foci contained solitary plants, and the proportion of foci with more plants decreased gradually; $9 \%$ of the foci harbored more than 10 plants each (Fig. 3).

In general, the P. elatius population in Kziv Creek was larger than that in A'mud Creek. Furthermore, as time passed, plant density decreased gradually. For example, on average, plant densities in A'mud Creek in January, February, and March 2008 were 31.5, 15, and 12.4 plants/strip, respectively (Fig. 1). Similar trends were observed for both seasons in these months (Fig. 2) and also in assessments performed before and after the assessments reported herein (data not presented).

Ascochyta blight symptoms were observed at both creeks in most strips. First disease symptoms were observed in November of each year. Although the incidence of symptomatic plants in some strips was high, the total leaf area exhibiting disease symptoms of individual plants was very low. Stem and pod infections were rarely observed at either creek at any assessment time. To the best of our judgment, plant mortality resulting from Ascochyta blight infections was very rare. From January through March 2008, disease incidence at A'mud Creek (67.6 to 90\%) exceeded the incidence recorded at Kziv Creek (65.1 to 47.5\%). However, in these months in 2009, disease incidence at both creeks reversed (Figs. 1 and 2). The incidence of diseased plants decreased over time at Kziv in 2008 and at both creeks in 2009 (Figs. 1 and 4). Observations in situ showed that the decrease in disease incidence resulted from shedding of symptomatic leaves, mainly from lower nodes. This phenomenon presumably enabled the plants to escape the disease, because they continued to grow and developed new leaves. Although there was wide variation in the incidence of symptomatic 
plants both within and between strips, there was no correspondence between plant density and incidence of diseased plants (Figs. 1 and 4).

Factors governing disease development over time in specific plants. In diseased plants, infections were initiated in the leaves of the lower nodes. Data recorded in the survey were used to calculate the correspondence between incidence of diseased plants and disease severity. After square-root transformation of disease severity records, the relationship between these two variables was found to be linear and highly significant, with $R^{2}$ values ranging from 0.824 to $0.954(P<0.01)$. It should be noted that differences in the slopes of the regression lines computed for the six comparisons ( 3 months $\times 2$ seasons) were minute, ranging from $0.069 \pm 0.019$ to $0.082 \pm 0.02$ (mean \pm standard deviation) (Fig. 5).

To further explore the diseased-leaf-dropping phenomenon, we artificially inoculated potted wild and domesticated Pisum plants with isolates originated from the respective hosts. Although the leaves of inoculated plants were still attached, disease severity of individual leaves was significantly affected by their position on the plant, with lower leaves being more diseased than upper ones. The
ANOVA test also showed significant effects of the interactions leaf position-inoculated host plant and isolate within host-inoculated host plant (Table 1; Fig. 6). After a while, severely infected P. elatius and P. fulvum leaves dropped off (Supplementary Fig. S2A) and, because the plants continued to grow and did not die, they overcame the disease and seemed healthy. No such leaf shedding occurred in the control plants (Supplementary Fig. S2B). However, diseased leaves of $P$. sativum did not drop but remained attached to the stems and, after a while, the pathogen invaded the stems, causing stem lesions that killed the upper plant parts (Supplementary Fig. S2D and E). These results corroborate our observations in natural ecosystems.

\section{DISCUSSION}

Results of the present study showed that Ascochyta blight was ubiquitous in P. elatius populations at both survey sites and in both seasons (Fig. 1). These results corroborate earlier observations made in other years and in other regions of Israel where P. elatius
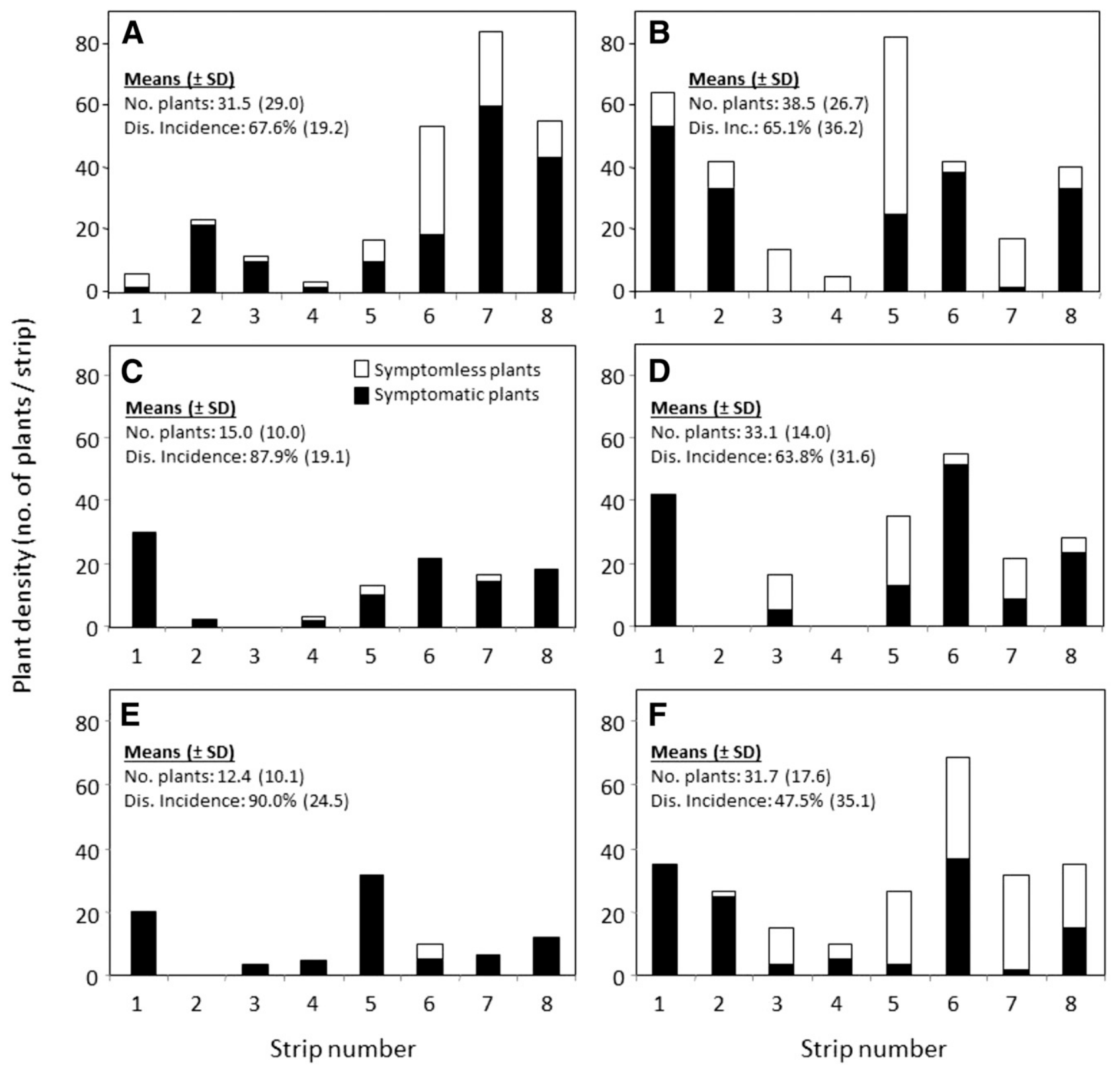

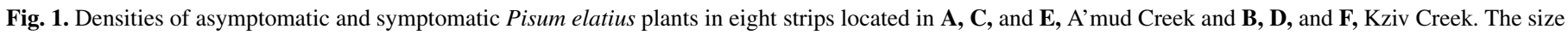

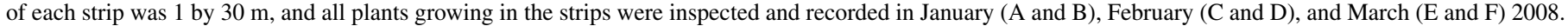
Symptomatic plants were infected with Peyronellaea pinodes, the causal agent of Ascochyta blight. SD = standard deviation. 
and $P$. fulvum are common (D. Shtienberg and O. Frenkel, unpublished data). In addition to past records of Ascochyta blight in wild Pisum spp. from Israel and Bulgaria (Dinoor 1974; Kaiser et al. 1998), Ascochyta blight infections on wild Pisum spp. observed in other countries, such as Turkey and Italy (S. Abbo and D. Shtienberg, personal observations), suggest that this disease is widely established in natural ecosystems. A search for the term "black spot in pea" in Google Scholar yielded 3,820 hits as compared with only 22 hits for the term "black spot in wild pea". Although anecdotal, this difference in search results highlights the immense gaps between our knowledge of agricultural systems and natural systems with respect to Ascochyta blight of pea. In our opinion, more attention should be devoted to the Pisum spp.-Peyronellaea pinodes pathosystem in natural ecosystems.

Our first objective was to document the density of Pisum elatius plants in natural ecosystems, and to elucidate the factors that determine their initial infection by Peyronellaea pinodes. The main findings were (i) Pisum elatius plants were dispersed spatially in aggregates, (ii) incidence of diseased $P$. elatius plants was not related to plant density, and (iii) Ascochyta blight symptoms were rarely seen on pods. Spatial distribution of organisms in natural habitats is governed by numerous factors, among which are local abiotic conditions, biotic interactions, physical barriers, dispersal capacity, environmental conditions, and human interventions (Boulangeat et al. 2012). In accordance with previous studies (Abbo et al. 2008, 2013b), results of the present study also showed that $P$. elatius plants were spatially dispersed in aggregates (Fig. 2).

It seems plausible that the spatial distribution of a pathogen evolved to be compatible with that of its host. Accordingly, it is likely that, under given environmental conditions, pathogens would initially establish themselves in sites occupied by dense populations of their hosts which, however, is dependent on the pathogens' modes of survival and propagule dispersal. Primary inoculum of Peyronellaea pinodes may originate from several distinct sources. If the primary inoculum of $P$. pinodes originated only from infected seed, chlamydospores that persisted in soil, or from pycnidia inhabiting infected plant stubble from the previous season, then development of initial disease symptoms would be expected to occur close to sites where the disease occurred in the previous season. This would be likely to happen in niches harboring dense Pisum elatius populations. However, the lack of correspondence between plant density and incidence of diseased plants that was found in the first disease assessments (Fig. 4A and B) implies that the primary inoculum of Peyronellaea pinodes may have originated from distant rather than local sources. Pycnidiospores are dispersed short distances by rain splashes whereas ascospores become airborne, and wind may blow the released ascospores as far as $1.6 \mathrm{~km}$ (Bretag et al. 2006; Khan et al. 2013; Roger and Tivoli 1996; Schoeny et al.
2007); therefore, these observations points to the significant role of the teleomorph stage in early stages of the epidemic in natural ecosystems. Indeed, it has been repeatedly demonstrated in the past that ascospores were the major source of initial inoculum in commercial pea crops (Bretag and Ramsey 2001; Roger and Tivoli 1996; Salam et al. 2011).

The second objective of the present study was to determine the factors governing disease development over time in individual plants. The main findings related to secondary spread were (i) Ascochyta blight severity was not related to rain quantity and (ii) the relationship between disease incidence and disease severity was relatively constant at both survey sites and over time. As indicated in Materials and Methods, the two survey sites differed in annual precipitation quantity; indeed, in the seasons covered by the survey, the differences exceeded the annual amount. From 1 October 2007 through 31 March 2008, there were 26 rainy days with a total of $233 \mathrm{~mm}$ of rain in A'mud creek; from 1 October 2008 to 31 March 2009 , there were 52 rainy days with a total of $668 \mathrm{~mm}$ of rain in Kziv creek. Contrary to our expectation, in March 2008, disease incidence averaged over all sites in A'mud creek was $91 \%$ and that over all sites in Kziv creek (with the higher rainfall) was $23 \%$. Disease severity values matched these records (Fig. 5). Secondary inoculum of $P$. pinodes consists of pycnidiospores and ascospores; both are formed during the growing season in lesions on leaves, stems, and pods. Whereas rain is essential for dissemination of pycnidiospores, ascospores are discharged not only after rainfall but also after

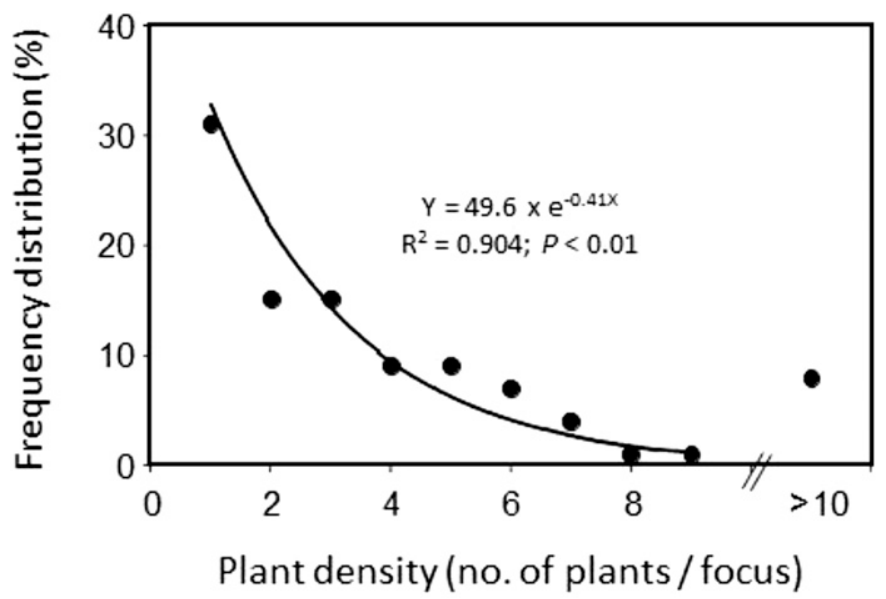

Fig. 3. Frequency distribution of Pisum elatius plant density in A'mud and Kziv Creeks in 2007-08 and 2008-09. Plants further apart than $1 \mathrm{~m}$ were regarded as growing in separate foci.
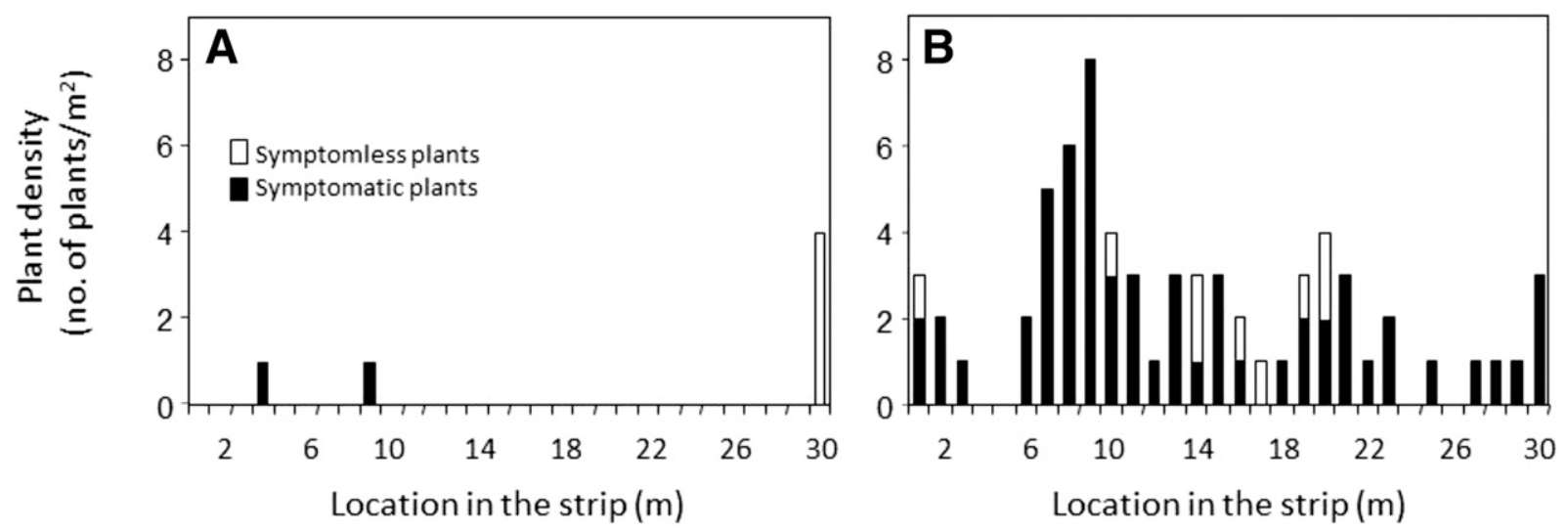

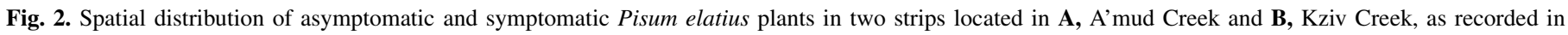

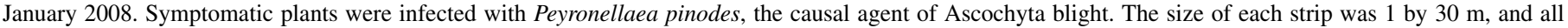
plants were inspected and recorded. 
periods with sufficient dew or high humidity (Bretag and Ramsey 2001; Roger and Tivoli 1996; Salam et al. 2011). Increased incidence results from plant-to-plant disease spread, and is partly related to distance from the inoculum source, whereas increased severity results from increased disease on a single plant or within an entity, and is related to localized dispersal events (Jeger et al. 1983; McRoberts et al. 2003; Seem 1984). If pycnidiospores had been the main mode of the secondary disease spread, the slopes of the incidence/severity relationships computed for the rainier 2008-09 season would have been expected to be steeper than those computed for the relatively dry 2007-08 season; and, similarly, slopes computed for Kziv creek would have been expected to be steeper than those computed for the A'mud creek. The lack of correspondence between rain quantity and Ascochyta blight infections and the relatively constant relationships between disease incidence and disease severity, between sites, and through time may suggest that ascospores, which are discharged in rainless but dewy conditions, were the principal source of secondary infections. This view accords with past studies of secondary disease spread in commercial pea fields (Bretag and Ramsey 2001; Roger and Tivoli 1996; Salam et al. 2011). Nevertheless, this assumption needs to be verified experimentally (for example, by trapping of pycnidiospores and ascospores) before drawing final conclusions.

Regarding the response of Pisum elatius plants to Peyronellaea pinodes, we determined that (i) the lower leaves of plants were more susceptible to $P$. pinodes infection than the upper leaves, (ii) severely infected Pisum elatius leaves dropped-off, (iii) stem lesions were rarely observed on diseased P. elatius plants, and (iv) Ascochyta blight epidemics in natural ecosystems were mild and did not devastate $P$. elatius populations. Controlled-environment experiments showed that the accessions of $P$. elatius and $P$. fulvum used in the present study were similarly susceptible to Peyronellaea pinodes as the commercial cultivar (control Pisum sativum). On all plants, the lower (i.e., older) leaves were more susceptible than the upper (i.e., younger) leaves (Fig. 6; Table 1). Variations in tissue susceptibility have previously been demonstrated (Richard et al. 2012; Tivoli and Banniza 2007) and were attributed to variations in the concentrations of the phytoalexin pisatin in the tissue (Heath and Wood 1971). However, in the present study, as time passed, substantial differences were observed between the domesticated cultivar and the two wild lines. Whereas diseased leaves of $P$. sativum remained attached to the plants, those of the wild Pisum spp. dropped off. The consequences were notable: in infected $P$. sativum plants, the pathogen had progressed along the leaf blades to the stems and formed stem infections that eventually killed the plants whereas, in the wild Pisum accessions, the plants survived, continued to grow, and, presumably were "cured". Although not observed in our present short-term experiments, in natural systems, falling diseased leaves remove the infected host tissues away from

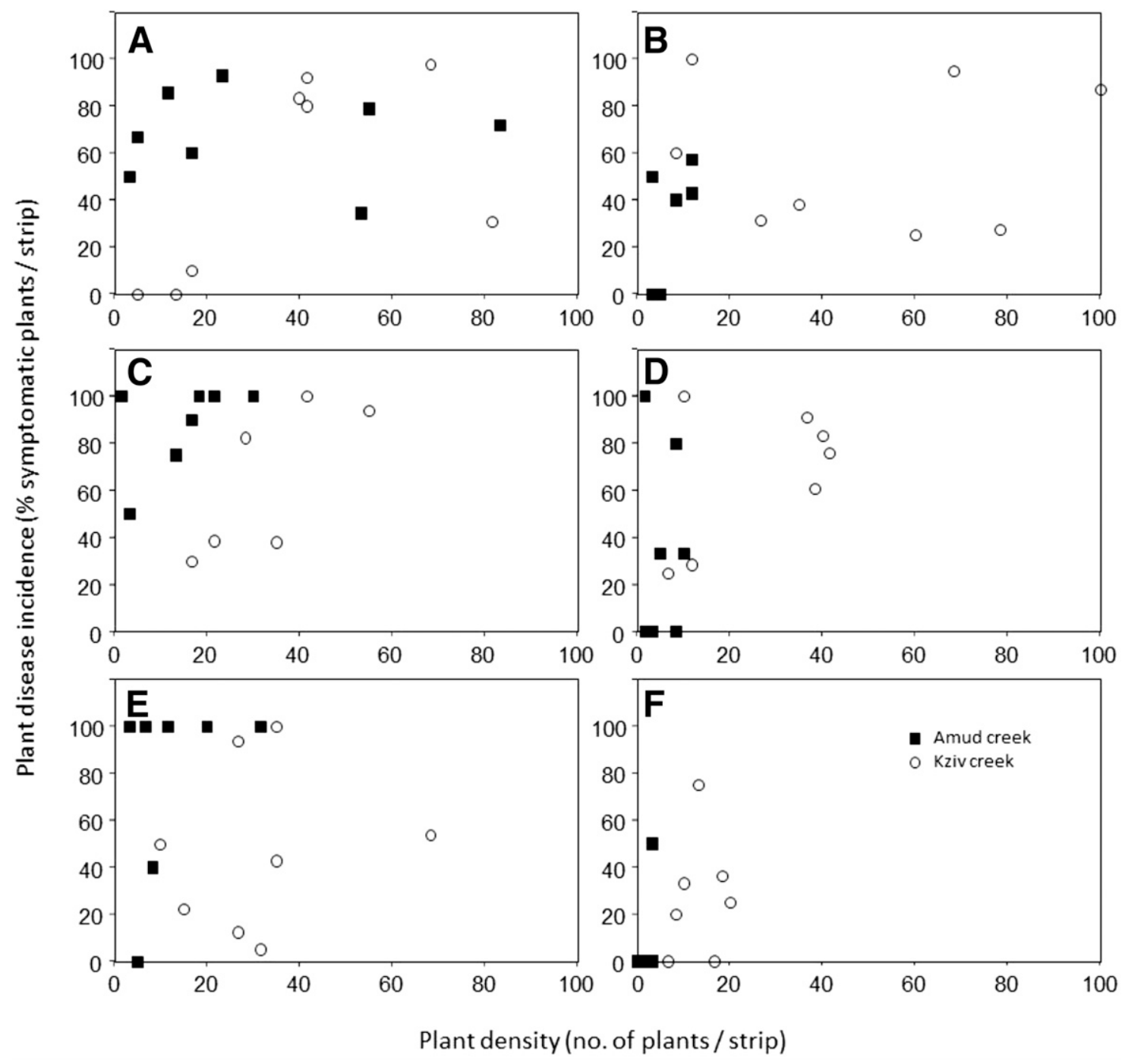

Fig. 4. Relationship between plant density and incidence of symptomatic Pisum elatius plants in eight strips located in A'mud and Kziv Creeks. The size of each strip was 1 by $30 \mathrm{~m}$, and all plants growing in the strips were inspected and recorded in A, January; C, February; and E, March 2008, and B, January; D, February; and F, March 2009. Symptomatic plants were infected with Peyronellaea pinodes, the causal agent of Ascochyta blight. 
the healthy upper leaves and, more importantly, away from the developing flowers and pods. These results are consistent with the statement of Dinoor and Eshed (1984), that plant disease epidemics in natural ecosystems rarely devastate the host plants and respective populations.

Dropping of diseased leaves is an interesting resistance mechanism. In fact, removal of diseased leaves is an effective management practice used for suppression of many diseases. For example, cutting and removing tomato leaves exhibiting gray mold symptoms precludes progressive development of the pathogen Botrytis cinerea from the leaf blades, via the petioles, to the stems. Unless this is done, stem lesions eventually girdle the stems and induce plant mortality (Shtienberg el al. 1998).

The mechanism by which Peyronellaea pinodes induces dropping of diseased Pisum elatius and P. fulvum leaves is not known. Peyronellaea pinodes produces several metabolites that are phytotoxic to Pisum and other plant species (Cimmino et al. 2012); the question of whether these metabolites induce diseased leaves to drop should be examined. In our experiments, we inoculated all Pisum spp. with the same fungal isolates but leaf dropping was observed only in the two wild species, which may imply that this trait is associated with the plant species rather than with the pathogen. Observations from other pathosystems might support this suggestion: Leveilulla taurica induces leaf dropping in pepper (Capsicum annuum) but not in tomato (Solanum lycopersicum); and Alternaria macrospora induces leaf dropping in Pima cotton
(Gossypium barbadense) but not in Acala cotton (G. hirsutum). Because dropping of diseased leaves may create an irreversible lag between host growth and epidemic development, thereby preventing formation of stem lesions and removing the infectious tissues away from the developing flowers and pods (Roger et al. 1999), it would be worthwhile to explore the potential of this resistance mechanism as an additional tool for Ascochyta blight management in pea.

TABLE 1. $P(\mathrm{~F})$ values from the analysis of variance applied to the data recorded in the experiment aimed at determining the factors governing susceptibility of Pisum leaves to Peyronellaea pinodes

\begin{tabular}{lcc}
\hline Source & df & $P(\mathrm{~F})$ values $^{\mathrm{a}}$ \\
\hline Original host plant $(\mathrm{OH})$ & 2 & 0.788 \\
Isolate within host $(\mathrm{I}[\mathrm{OH}])$ & 3 & 0.514 \\
Inoculated host plant $(\mathrm{CH})$ & 2 & 0.188 \\
Leaf position $(\mathrm{LP})$ & 3 & $<\mathbf{0 . 0 0 0 1}$ \\
$\mathrm{OH} \times \mathrm{CH}$ & 4 & 0.914 \\
$\mathrm{OH} \times \mathrm{LP}$ & 6 & $\mathbf{0 . 0 1 7}$ \\
$(\mathrm{I}[\mathrm{OH}]) \times \mathrm{CH}$ & 6 & $\mathbf{< . 0 0 0 1}$ \\
$(\mathrm{I} \mathrm{OH}]) \times$ LP & 9 & 0.707 \\
$\mathrm{CH} \times \mathrm{LP}$ & 6 & 0.061 \\
$\mathrm{OH} \times \mathrm{CH} \times \mathrm{LP}$ & 12 & 0.614 \\
$(\mathrm{I}[\mathrm{OH}]) \times \mathrm{CH} \times \mathrm{LP}$ & 18 & 0.941 \\
\hline
\end{tabular}

${ }^{a}$ Numbers in bold indicate significant effects.
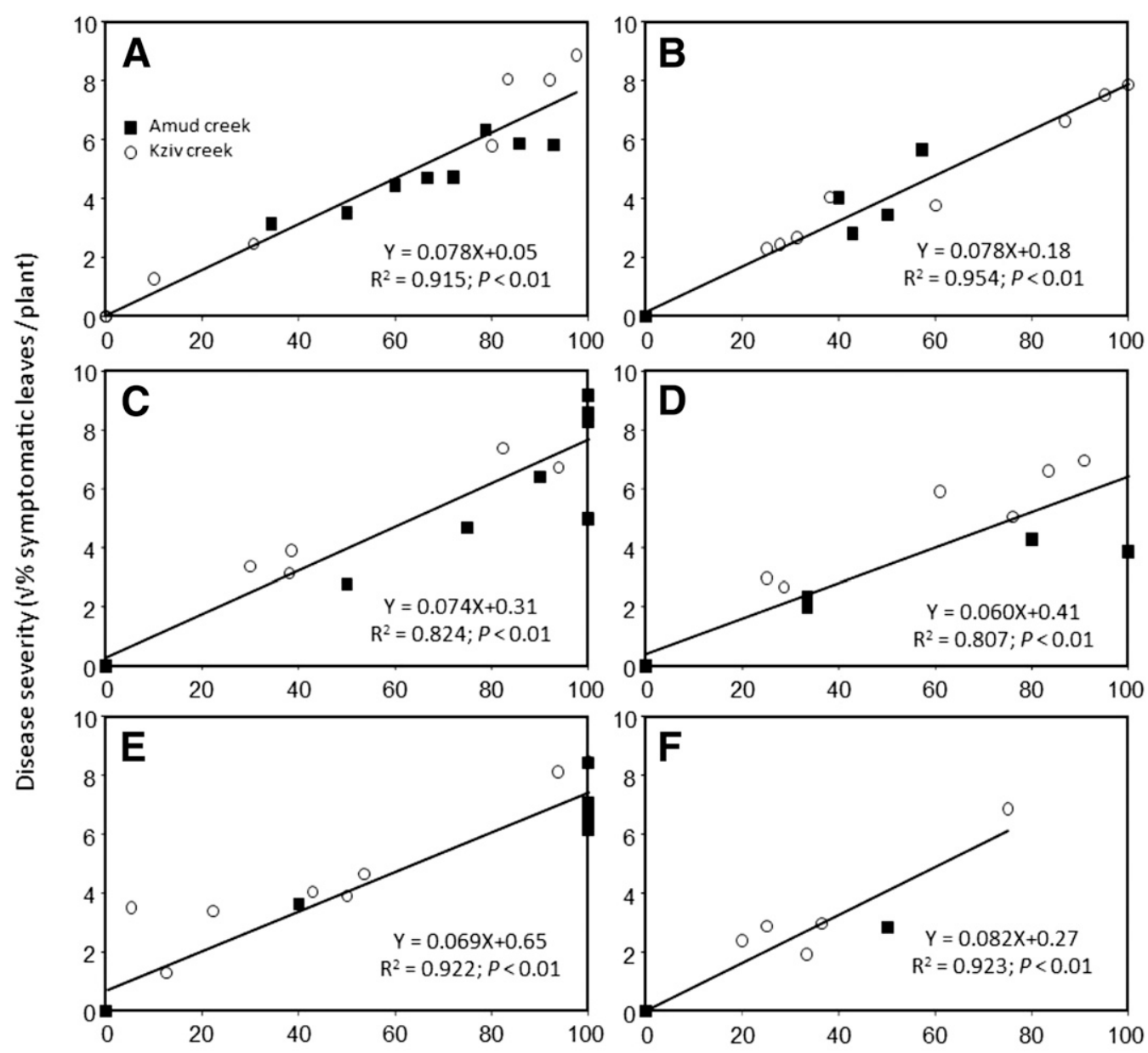

Plant disease incidence (\% symptomatic plants / strip)

Fig. 5. Relationship between the incidence of diseased Pisum elatius plants and the severity of the disease in 16 strips located in A'mud and Kziv Creeks. The size of each strip was 1 by $30 \mathrm{~m}$, and all plants growing in the strips were inspected in A, January; C, February; and E, March 2008, and B, January; D, February; and F, March 2009. Symptomatic plants were infected with Peyronellaea pinodes, the causal agent of Ascochyta blight. In each graph, the regression lines were computed for the pooled data from both creeks. 
Recently, Golani et al. (2016) suggested that Israel is inhabited by a single metapopulation of $P$. pinodes. The findings of the present study are in line with their suggestion. This implies that $P$. pinodes might migrate from wild Pisum spp. to domesticated plants, and
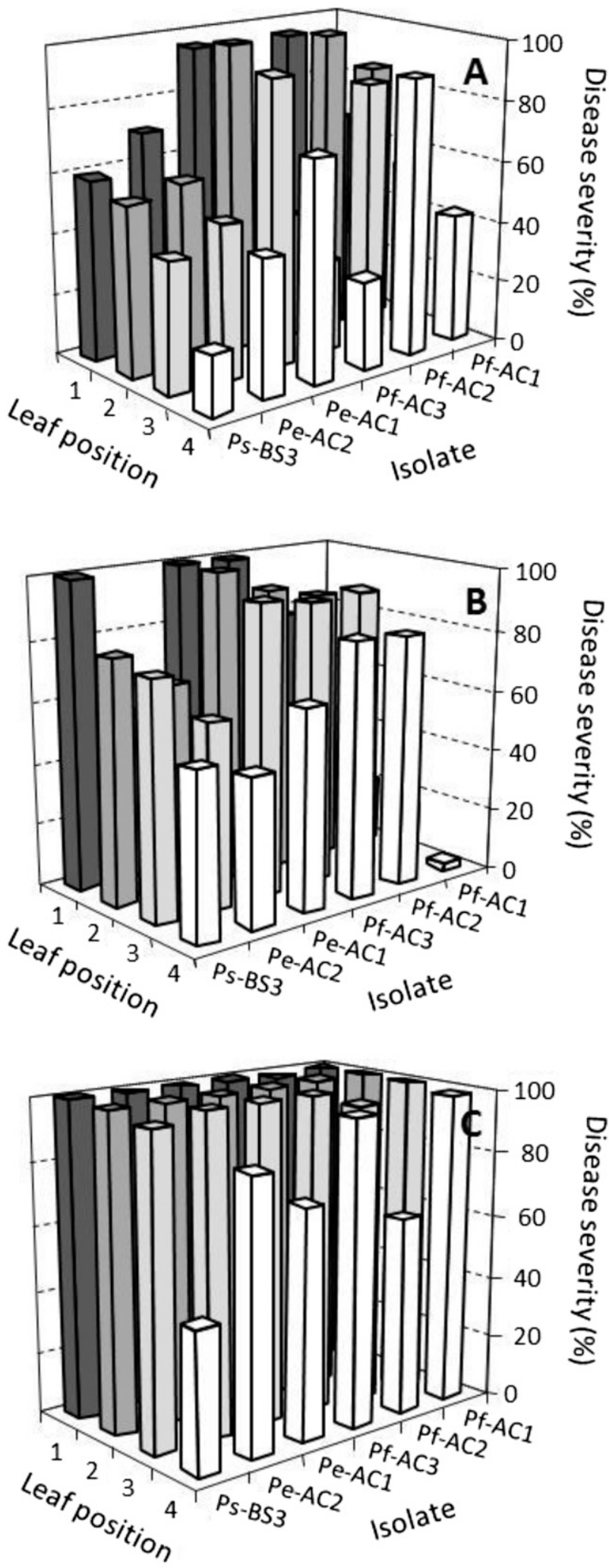

Fig. 6. Changes in leaf susceptibility (position $1=$ the oldest leaf) of wild and domesticated Pisum plants challenged with six Peyronellaea pinodes isolates. A, Pisum elatius; B, P. fulvum; and C, P. sativum. Isolates were originated from P. sativum (Ps), P. elatius (Pe), and P. fulvum (Pf). The experiment was performed on potted plants, and Ascochyta blight severity was recorded 8 days after inoculation. vice versa. In light of the large numbers of Pisum plants growing per unit area in agricultural ecosystems as compared with the demography of natural ecosystems, and considering the amount of infectious host tissue that potentially might develop in the two respective demes, it seems likely that the amount of inoculum that could develop in agricultural fields is much greater than that in natural ecosystems. This implies that, in areas where Pisum plants prevail in sympatric agricultural/natural ecosystems, the former could supply inoculum to the latter. However, in areas where Pisum plants are widespread in natural ecosystems and pea is not commonly cultivated, soon after introduction of this crop, the wild Pisum populations could serve as a source of primary inoculum of $P$. pinodes in the commercial pea fields.

\section{ACKNOWLEDGMENTS}

This study was supported by the Chief Scientist of Israel's Ministry of Agriculture and Rural Development. Contribution Number 555/15 from ARO, the Volcani Center, POB 6, Bet-Dagan 50250, Israel. S. Abbo is the incumbent of the Jacob and Rachel Liss Chair in Agronomy, the Hebrew University of Jerusalem, Rehovot, Israel.

\section{LITERATURE CITED}

Abbo, S., Lev-Yadun, S., Heun, M., and Gopher, A. 2013a. On the 'lost' crops of the Neolithic Near East. J. Exp. Bot. 64:815-822.

Abbo, S., Zezak, I., Schwartz, E., Lev-Yadun, S., and Gopher, A. 2008. Experimental harvest of wild pea in Israel: Implications for the origin of Near Eastern farming. J. Archaeol. Sci. 35:922-929.

Abbo, S., Zezak, I., Zehavi, Y., Schwartz, E., Lev-Yadun, S., and Gopher, A. 2013b. Six seasons of wild pea harvest in Israel: Bearing on Near Eastern plant domestication. J. Archaeol. Sci. 40:2095-2100.

Ben-Ze'ev, N., and Zohary, D. 1973. Species relations in the genus Pisum L. Isr. J. Bot. 22:73-91.

Boulangeat, I., Gravel, D., and Thuiller, W. 2012. Accounting for dispersal and biotic interactions to disentangle the drivers of species distributions and their abundances. Ecol. Lett. 15:584-593.

Bretag, T. W., Keane, P. J., and Price, T. V. 2006. The epidemiology and control of Ascochyta blight in field peas: A review. Aust. J. Agric. Res. 57:883-902.

Bretag, T. W., and Ramsey, M. D. 2001. Foliar diseases caused by fungi: Ascochyta spp. Pages 24-28 in: Compendium of Pea Diseases and Pests. J. M. Kraft and F. L. Pfleger, eds. American Phytopathological Society, St. Paul, MN.

Cimmino, A., Andolfi, A., Fondevilla, S., Abouzeid, M. A., Rubiales, D., and Evidente, A. 2012. Pinolide, a new nonenolide produced by Didymella pinodes, the causal agent of Ascochyta blight on Pisum sativum. J. Agric. Food Chem. 60:5273-5278.

Clulow, S. A., Lewis, B. G., and Matthews, P. 1991. A pathotype classification for Mycosphaerella pinodes. J. Phytopathol. 131:322-332.

Davidson, J. A., Hartley, D., Priest, M., Krysinska-Kaczmarek, H., McKay, A., and Scott, E. S. 2009. A new species of Phoma causes Ascochyta blight symptoms on field peas (Pisum sativum) in South Australia. Mycologia 101:120-128.

Davies, D. R. 1993. The pea crop. Pages 1-12 in: Peas: Genetics, Molecular Biology and Biotechnology. R. Casey and D. R. Davies, eds. CAB International, Wallingford, UK.

Davis, P. H. 1970. Pisum L. Pages 370-372 in: Flora of Turkey, Vol. 3. P. H. Davis, ed. Edinburgh University Press, Edinburgh, UK.

Dinoor, A. 1974. Role of wild and cultivated plants in the epidemiology of plant diseases in Israel. Annu. Rev. Phytopathol. 12:413-436.

Dinoor, A., and Eshed, N. 1984. The role and importance of pathogens in natural plant communities. Annu. Rev. Phytopathol. 22:443-466.

Ellis, T. H. N. 2010. Pisum. Pages 237-248 in: Wild Crop Relatives: Genomic and Breeding Resources, Legume Crops and Forages. C. Kole, ed. SpringerVerlag, Berlin, Heidelberg.

FAOSTAT. 2013. FAOSTAT, Production, Crops. Online publication. Food and Agriculture Organization of the United Nations. http://faostat.fao.org/site/ 567/DesktopDefault.aspx?PageID=567ancor

Fondevilla, S., Avila, C. M., Cubero, J. I., and Rubiales, D. 2005. Response to Mycosphaerella pinodes in a germplasm collection of Pisum spp. Plant Breed. 124:313-315.

Gladieux, P., Feurtey, A., Hood, M. E., Snirc, A., Clavel, J., Dutech, C., Roy, M., and Giraud, T. 2015. The population biology of fungal invasions. Mol. Ecol. 24:1969-1986

Golani, M., Abbo, S., Sherman, A., Frenkel, O., and Shtienberg, D. 2016. The temperature response and aggressiveness of Peyronellaea pinodes isolates originating from wild and domesticated Pisum sp. in Israel. Phytopathology 106:824-832. 
Heath, M. C., and Wood, R. K. S. 1971. Role of inhibitors of fungal growth in the limitation of leaf spots caused by Ascochyta pisi and Mycosphaerella pinodes. Ann. Bot. (Lond.) 35:475-491.

Jeger, M. J., Jones, D. G., and Griffiths, E. 1983. Disease spread of nonspecialized fungal pathogens from inoculated point sources in intraspecific mixed stands of cereal cultivars. Ann. Appl. Biol. 102:237-244.

Jha, A. B., Warkentin, T. D., Gurusamy, V., Tar'an, B., and Banniza, S. 2012. Identification of Mycosphaerella blight resistance in wild Pisum species for use in pea breeding. Crop Sci. 52:2462-2468.

Jing, R., Ambrose, M. J., Knox, M. R., Smykal, P., Hybl, M., Rams, A., Caminero, C., Burstin, J., Duc, G., van Soest, L. J. M., Swiecicki, W. K., Pereira, M. G., Vishnyakova, M., Davenport, G. F., Flavell, A. F., and Ellis, T. H. N. 2012. Genetic diversity in European Pisum collections. Theor. Appl. Genet. 125:367-380.

Jing, R., Vershinin, A., Grzebyta, J., Shaw, P., Smykal, P., Marshall, D., Ambrose, M. J., Ellis, T. H. N., and Flavell, A. 2010. The genetic diversity and evolution of field pea (Pisum) studied by high throughput retrotransposon based insertion polymorphism (RBIP) marker analysis. BMC Evol. Biol. 10:44.

Jones, L. K. 1927. Studies on the nature and control of blight, leaf and pod spot, and foot-rot of peas caused by species of Ascochyta. NY State Agric. Exp. Stn. Res. Rep. 547:1-46.

Kaiser, W., Muehlbauer, F. J., Hannan, R. M., and Mihov, M. 1998. First report of natural infection of Pisum sativum subsp. elatius by Mycosphaerella pinodes in Bulgaria. Plant Dis. 82:830.

Khan, T. N., Timmerman-Vaughan, G. M., Rubiales, D., Warkentin, T. D., Siddique, K. H. M., Erskine, W., and Barbetti, M. J. 2013. Didymella pinodes and its management in field pea: Challenges and opportunities. Field Crops Res. 148:61-77.

Ladizinsky, G., and Abbo, S. 2015. The search for wild relatives of cool season legumes. Springer Briefs in Plant Science. Springer, Heidelberg.

Le May, C., Guibert, M., Baranger, A., and Tivoli, B. 2014. A wide range of cultivated legume species act as alternative hosts for the pea Ascochyta blight fungus, Didymella pinodes. Plant Pathol. 63:877-887.

Mattatia, J. 1977. Amphycarpy and variability in Pisum fulvum. Bot. Notiser 130:27-34.

Maxted, N., and Ambrose, M. 2001. Peas (Pisum L.). Pages 181-190 in: Plant Genetic Resources of Legumes in the Mediterranean. N. Maxted and S. J. Bennett, eds. Kluwer, Dordrecht, The Netherlands.

McRoberts, N., Hughes, G., and Madden, L. V. 2003. The theoretical basis and practical application of relationships between different disease intensity measurements in plants. Ann. Appl. Biol. 142:191-211.
Morisita, M. 1962. $I_{\delta}$ Index, a measure of dispersion on individuals. Res. Popul. Ecol. (Kyoto) 4:1-7.

Muehlbauer, F. J., Kaiser, W. J., and Simon, C. J. 1994. Potential for wild species in cool season food legume breeding. Euphytica 73:109-114.

Peever, T. L., Barve, M. P., Stone, L. J., and Kaiser, W. J. 2007. Evolutionary relationships among Ascochyta species infecting wild and cultivated hosts in the legume tribes Cicereae and Vicieae. Mycologia 99:59-77.

Richard, B., Jumel, S., Rouault, F., and Tivoli, B. 2012. Influence of plant stage and organ age on the receptivity of Pisum sativum to Mycosphaerella pinodes. Eur. J. Plant Pathol. 132:367-379.

Roger, C., and Tivoli, B. 1996. Spatio-temporal development of pycnidia and perithecia and dissemination of spores of Mycosphaerella pinodes on pea (Pisum sativum). Plant Pathol. 45:518-528.

Roger, C., Tivoli, B., and Huber, L. 1999. Effects of temperature and moisture on disease and fruit body development of Mycosphaerella pinodes on pea (Pisum sativum). Plant Pathol. 48:1-9.

Salam, M. U., Galloway, J., Diggle, A. J., MacLeod, W. J., and Maling, T. 2011. Predicting regional-scale spread of ascospores of Didymella pinodes causing Ascochyta blight disease on field pea. Australas. Plant Pathol. 40: 640-647.

Schoeny, A., Jumel, S., Rouault, F., Le May, C., and Tivoli, B. 2007. Assessment of airborne primary inoculum availability and modelling of disease onset of Ascochyta blight in field peas. Eur. J. Plant Pathol. 119:87-97.

Seem, R. C. 1984. Disease incidence and severity relationships. Annu. Rev. Phytopathol. 22:133-150.

Shtienberg, D., Elad, Y., Niv, A., Nitzani, Y., and Kirshner, B. 1998. Significance of leaf infection by Botrytis cinerea in stem rotting of tomatoes grown in non-heated greenhouses. Eur. J. Plant Pathol. 104:753-763.

Stukenbrock, E. H., and McDonald, B. A. 2008. The evolutionary emergence of plant pathogens in agroecosystems. Annu. Rev. Phytopathol. 46:75-100.

Tivoli, B., and Banniza, S. 2007. Comparison of the epidemiology of Ascochyta blights on grain legumes. Eur. J. Plant Pathol. 119:59-76.

Vershinin, V. A., Allnutt, T. R., Knox, M. R., Ambrose, M. J., and Ellis, T. H. N. 2003. Transposable elements reveal the impact of introgression, rather than transposition, in Pisum diversity, evolution and domestication. Mol. Biol. Evol. 20:2067-2075.

Waines, J. G. 1975. The biosystematics of peas (Pisum L.). Bull. Torrey Bot. Club 102:385-395.

Weimer, J. L. 1947. Resistance of Lathyrus spp. and Pisum spp. to Ascochyta pinodella and Mycosphaerella pinodes. J. Agric. Res. 75:181-190.

Wroth, J. M. 1998. Possible role for wild genotypes of Pisum spp. to enhance Ascochyta blight resistance in pea. Aust. J. Exp. Agric. 38:469-479. 